\title{
Afferent Pathway
}

National Cancer Institute

\section{Source}

National Cancer Institute. Afferent Pathway. NCI Thesaurus. Code C13080.

A sensory pathway that conducts impulses toward the central nervous system. 